\title{
Correction to: Improving Nocturnal Hypoxemic Burden with Transvenous Phrenic Nerve Stimulation for the Treatment of Central Sleep Apnea
}

\author{
Olaf Oldenburg ${ }^{1,2,3} \cdot$ Maria Rosa Costanzo ${ }^{4} \cdot$ Robin Germany $^{5} \cdot$ Scott McKane $^{5} \cdot$ Timothy E. Meyer $^{5} \cdot$ Henrik Fox $^{1,3}$ (I)
}

Published online: 10 November 2021

○) Springer Science+Business Media, LLC, part of Springer Nature 2021

\section{Correction to: Journal of Cardiovascular Translational Research (2021) 14:377-385 https://doi.org/10.1007/s12265-020-10061-0}

Due to an error during the production process, Tables 2 and 3 as submitted had the median on one row and the quartiles on the row below, but the formatting of the tables in the article as originally published accidentally merged them together.

The original article has been corrected.

Publisher's Note Springer Nature remains neutral with regard to jurisdictional claims in published maps and institutional affiliations.

The original article can be found online at https://doi.org/10.1007/ s12265-020-10061-0.

Henrik Fox

akleemeyer@hdz-nrw.de

1 Clinic for Thoracic and Cardiovascular Surgery, Herzund Diabeteszentrum NRW, Ruhr-Universität Bochum, Bad Oeynhausen, Germany

2 Ludgerus-Kliniken Münster, Clemenshospital, Münster, Germany

3 Heart Failure Department, Herz- und Diabeteszentrum NRW, Ruhr-Universität Bochum, Georgstr. 11, D-32545 Bad Oeynhausen, Germany

4 Advocate Heart Institute, Naperville, IL, USA

5 Respicardia, Inc, Minnetonka, MN, USA 